\title{
Habituating Pain: Questioning Pain and Physical Strain as Inextricable Conditions in the Construction Industry
}

I Jeppe Z. N. Ajslev'

Ph.D. fellow, Centre for Working Life Research, Roskilde University

I Henrik L. Lund

Associate professor, Centre for Working Life Research, Roskilde University

I Jeppe L. Møller

Ph.D. fellow, Centre for Working Life Research, Roskilde University

I Roger Persson

Associate professor, Department of Psychology, Division of Work- and Organizational Psychology, Lund University

I Lars L. Andersen

Professor, National Research Centre for the Work Environment

\begin{abstract}
In this article, we investigate the relations between discursive practices within the Danish construction industry and the perceived pain, physical deterioration, and strain affecting the construction workers. Of central importance is the widely accepted hegemonic discourse on physical strain and pain as unavoidable conditions in construction work.

Based on 32 semi-structured interviews performed in eight case studies within four different construction professions, workers' descriptions of physical strain and its relation to the organizational and social context are analyzed through concepts of subject positioning in discursive practice and a focus on power relations.

The analysis shows that workers and employers reproduce certain types of traditional working class masculinities and search for high-pace productive working rhythms, which in combination with economic incentives common within the industry reproduce physical strain and the habituation of pain as unquestioned conditions in construction work. The understanding of this mutual reinforcement of the necessity of physically straining, painful, high-paced construction work provides fruitful perspectives on the overrepresentation of musculoskeletal deterioration within construction work and also sheds light on some of the difficulties in addressing and changing occupational health and safety practices in the construction industry.
\end{abstract}

\section{KEY WORDS}

Brutal rhythms / conditional orientation / construction work / deterioration / habituation / health / masculinity / musculoskeletal disorder / pain / physical strain / safety culture

\footnotetext{
${ }^{1}$ E-mail: jza@ruc.dk
} 


\section{Introduction}

onstruction work around the world has historically been a field of work characterized by high levels of physical strain (Andrésen 1984; Applebaum 1999; Morton 2002). It is characterized by high work pace (NFA 2012), heavy lifting, dragging, and pulling and requires people to work in awkward positions (e.g., hands above shoulders, knees or back bent (Bach et al. 2011)). In biomedical and epidemiological research, this kind of physically straining work involving heavy loads and high work pace has been shown to be associated with physical deterioration and musculoskeletal disorders (MSDs) (Andersen et al. 2007; Andersen et al 2012). MSDs are sometimes characterized by specific medical symptoms but more often by nonspecific pain or soreness in neck/ shoulder, arm/hand, back, or knees (Waddell 2006).

Compared with other job groups in Denmark, construction workers experience a very high degree of postwork body pains and fatigue (NFA 2012). Eriksen et al. show that pain, especially in the lower back, can lead to long-term disability (1998). Physically straining work is one of the main reasons for early retirement in the construction industry (the Danish Construction Association 2006; Frøyland et al. 2004). In addition, workers suffering from MSDs have an increased risk of losing work ability in their profession, being excluded from the labor force, and becoming physically impaired, with loss of well-being as a consequence (Mortensen et al. 2008). Further, MSD increases the risk of future long-term sickness absence (Andersen et al. 2012), and higher levels of musculoskeletal pain in the neck, back, and knees are associated with progressively higher risk for long-term sickness absence (Andersen et al. 2011). Also, a ten-year German cohort study has shown musculoskeletal diseases to make for $45 \%$ of the disability pensioning in the construction industry (Arndt et al. 2005).

From a historical perspective, there has been much effort to reach a more sustainable physical workload and to reduce physical deterioration in the construction industry. Since the late 19th century, labor unions in particular have fought for initiatives that focus on reducing wear and tear of the construction worker. This focus has been sustained and developed throughout the 20th century and is described in both Danish and international research (examples are Andrésen 1984; Frøyland et al. 2004; Gherardi \& Nicolini 2002; Hasle 1982).

Until now, most MSD research in the construction industry has primarily focused on the approximate ergonomic and biomedical problems. However, recent research on work and deterioration as well as domestic political agenda on occupational health and safety suggest that MSD problems should be resolved through more interdisciplinary approaches (MSD-committee report 2010; Westgaard \& Winkel 2011); there is an imminent need to study and approach deterioration and physical strain in the construction industry by the inclusion of social theory and methodology aiming to understand the interrelation of body, identity, and context. This necessity is underlined by research indicating that psychosocial perspectives in the job situation have a considerable impact on the prevalence of MSD (Mortensen et al. 2008; Waddell \& Burton 2006).

In this article, we investigate the relations between construction workers' discursive practices and the perceived strain and physical deterioration in the construction industry. While physical strain and deterioration are commonly accepted as unavoidable consequences of construction work among researchers and actors within the construction industry (Vad \& Kines 2011), we challenge this discourse by including perspectives on social relations of power in the analysis of work and culture within the industry. 
As occupational health and safety in the construction industry is widely known for the lack of measurable impact from efforts for improvement (Dyreborg 2006; Morton 2002), this article also provides possible explanations as to why earlier preventive measures and interventions have seemingly had little or no effect despite many years of endeavors.

\section{Construction workers in work gangs and the framing of the conditional orientation}

In the Danish construction industry, work is usually organized in small self-organizing groups known as construction gangs. Gang organization is widely perceived as an appropriate solution, both by the workers themselves and by the parties in the Danish construction industry since many tasks require on-the-spot collaboration and coordination. The construction gang has traditionally managed the direct supervision of the work with the foreman as democratically elected leader. This kind of self-management encompasses division of labor, cooperation, and working methods. Workers in this type of organization are believed to have great opportunity to influence their own work (Andrésen 1984; Hasle 1982). And influence is from several theoretical perspectives perceived as resource-building and associated with positive expectations and feelings of mastery and therefore believed to promote both good mental and physical health (Hvid 2009; Karasek \& Theorell 1990; Ursin 2004).

As a phenomenon, gang organization is embedded in the complex relationships between legislation, labor market, companies, trade unions, employers' associations, types of organization and management, culture, traditions, workers' subjective orientations, etc. All of these factors contribute to the context of the construction workers' conduct in relation to handling physically straining work and the associated risks of physical deterioration. One could address this issue from a coping perspective studying how people manage their life conditions (Lazarus 1999). But rather than focusing on the individual worker's way of coping, we study how social practices of dealing with the physical strain are presented and influence workers' practices. Our focus in this article is aimed at the gang as the everyday framework for social contact and daily collaboration between workers as it must be understood as a main arena for production of professional and social identities and meaning through discursive practice; a term defined by Bronwyn Davies and Rom Harré as "all the ways in which people actively produce social and psychological realities" (1990, p. 22). This further implicates that norms and ethics of handling physical strain as well as considerations for bodily well-being come into practice through discursive practices and thus relations of power in the gang.

The workers' conceptualizations and practices of body, deterioration, and physical strain in the work become significant perspectives in the investigation of the discursive practice reproducing these norms and ethics. By shedding some light on these norms and ethics, we gain better optics for perceiving and identifying when workers reproduce norms that could either lessen the physical strain they take upon themselves or norms that seem to support a culture of acceptance or accommodation of physical strain.

Recent research on the topic of construction workers' perceptions of straining work conditions show that workers describe strain and deterioration as a "fatalistic phenomenon, difficult if not impossible to prevent" (Vad \& Kines 2011, p. 8). Since such a conceptualization of the relation between work and physical strain and deterioration 
is likely to pose a substantial complication for preventive actions against MSDs, it is important to explore the social dynamics behind its maintenance. Our empirical studies support the notion that certain hegemonic discourse upon physical strain and deterioration as unavoidable conditions within work is reproduced at all levels in the construction industry. In order to conceptually define and grasp this phenomenon, we propose the term conditional orientation for this form of practice where subjects take the dominant discourse for granted and (re)position themselves accordingly in everyday life.

As an analytical concept thought to expand our vocabulary on a certain kind of subjectification (Foucault 1983), the conditional orientation is not to be perceived as some stable or objective character trait within the studied subjects. Rather, it is a concept allowing for analytical discussion of a certain discursive reproduction of subjectivity at the level of the individual and the group.

The concept of conditional orientation draws upon an understanding that discourses (collective interpretations) on a topic (object/subject) can take hegemonic forms-very shortly stated-in the sense that they become almost the sole common conception of truth on a given phenomenon (Foucault 1976; Laclau \& Mouffe 1985). The conditional orientation as a concept is developed on the notion of hegemonic discourse but is to be understood very specifically in the sense that it points to a certain subjective orientation in relation to the discursive production of "conditions" within work or other activity (construction work for instance) ${ }^{2}$-namely an orientation that accepts the necessity of a certain type of behavior as foundational for participation.

To specify the conditional orientation in relation to the social context and behavior of construction workers, we draw upon the concept of habitus. Habitus is described by Bourdieu as the behaviors, the benefits, and the practices characterizing an individual or a group. These practices lead to all the forms of "reasonable" or "common sense" behavior that is enabled within the boundaries of the group, because they are ultimately founded on the basis of existence-shared by the group-that puts life and family relations under social and economic coercion (Bourdieu 1996). The habitus of Danish construction workers as such is to be understood as social practices that have a certain meaning in relation to discursive perception of contemporary conditions in the industry. The discursive perception of these conditions frames the room for agency in relation to what types of behavior can be positively sanctioned in the social context of construction work. Therefore, for a certain practice to become part of the construction workers' habitus-become habituated-we argue that it has to rely on a certain perception of the conditions of work. While always leaving room for negotiation and variation in practices, this leaves plenty of options for different sorts of agency, but will inevitably also limit the options for agency in certain areas of work.

As we draw upon an understanding of conditions as discursive productions, ${ }^{3}$ the phenomenon "physically straining work as a condition in the construction industry" can and shall not be interpreted as the final explanation to the behavior of the construction workers. Rather habituation of certain types of behavior is produced by the rationalities tying social or material benefit or usability to certain types of conduct in relation to physically straining work.

Following this argument, the final specification of the conditional orientation lies in its focus on the individual's relation to the rationalities structuring the agency of the individual and group. The conditional orientation is focused on the area that can be defined and centered upon the individual's perception of power, control, influence, and/ 
or agency in relation to the given phenomenon. Here, the conditional orientation is to be defined as a specific part of the subject's relation, namely a relation characterized by powerlessness, as also emphasized by Bronwyn Davies and Rom Harré in their work on positioning theory (1990). The singular focus on this powerless relation is what distinguishes the conditional orientation from the concept of habitus, as habitus consists of all the practices belonging to the individual or group, not only the ones to which people see no apparent alternative.

The conditional orientation is in short the subjects perceived powerless relation to a phenomenon - and it can be evoked any place where rationalities tie agency by gaining the character of hegemonic discourses-realities.

In the discussion of agency, however, it then becomes clear that the conditional orientation-at the same exact time as it and the rationalities on which it persists are articulated-has the potential to change its character in the discursive practices, as a different reflexivity may lead to another sense of agency. Herein lies also potentials for addressing the challenges of MSD in the construction industry as new perspectives can potentially accomplish new reflection.

In any event, as follows from a social constructionist understanding of knowledge, the representations of phenomena of work always present themselves to the mind of the interpreter as the best, or most dominant, current perspectives on a subject of study (Foucault 2005; Gergen 2001; Haraway 1991). Therefore, as a notion pointing to essentialist or inevitable coherences, such conditional orientation should never satisfy social research as final explanations but rather encourage further critical inquiry. As a dominant discourse, the conditional orientation toward physical strain and deterioration as inextricable conditions in construction work becomes very important to challenge in order to gain insights into the logics and rationalities this discourse consists of.

\section{Analytical framework}

In order to understand how the conditional orientation toward physical strain and deterioration is reproduced in the construction gang, we draw upon an understanding of social context as an ongoing series of negotiation of subject positions through speechactions into discursive practice proposed by Davies and Harré (1990).

This negotiation takes place through the workers' participation and communication in the construction gang, and contributes to the ongoing reproduction of the common social practice or habitus (Bourdieu 1996). By focusing on speech-actions whereby the worker creates certain subject positions for himself and his colleagues, the reproduction of this practice can be dissected and analyzed (Davies \& Harré 1990). Gherardi and Nicolini describe this type of speech-actions in relation to safety culture as identifiable via generalizing operators (2002). This means that in order to understand the subject positions, reproduced in the discursive practice of the construction gang, analytical emphasis is put into phrases naturalizing certain social practices such as "one must," "you know," "one will," "of course," and so on. These generalizing operators function by exalting a view or perspective to the status of common truth in the social construction of reality, and by emphasizing certain characteristics as being important in relation to the given topic, for instance, the characteristics of an ideal construction worker. The use of this sort of subject positions is in daily practice installed through either 
reflexive positioning, whereby a person positions him-/herself in relation to other(s) or to a perceived discourse or object, or through interactive positioning through which one person positions another (Davies \& Harré 1990).

When positioning oneself, or being positioned by others, a participant in the discursive practice has the opportunity to either conform to the positioning or to negate it, that is, to take a different stance than the one offered through the dialogue. Importantly, when conforming to or negating positions, we become emotionally committed. In this way, the practice of positioning produces our sense of identity (Davies \& Harré 1990). This means that when construction workers conform or negate certain positions in relation to physically straining work, it has an impact on their sense of professional identity, which again is drawn upon when reproducing the demands and norms in relation to other gang members and coworkers. ${ }^{4}$

In addition to the positioning theory, we further employ an analytics of power inspired by Foucault $(1977,1978,1983)$, in that we focus not only on the identities created through the discursive positioning but also on the rationalities referred to by the interviewed construction workers. We use this analytical tool because it shows which ideas, norms, values, and forms of incitement exercise a power in the discursive practice of the construction workers. This is very important as it confers an insight into the rationalities guiding the construction workers' conduct in relation to handling physical strain, pain, work, and their bodies. This is an approach that moves the analysis from descriptions of what (as for instance, what does the ideal worker do) and how (how does he do it) to the level of why; to descriptions of what the construction workers refer to as the reasons for conducting themselves as they do. Understanding the motives for the present forms of agency seems to us to be very central in understanding how to address the issues contributing to MSDs in the construction industry, and must be perceived as pivotal to explaining why the conditional orientation persists.

Employing these analytical tools, we commence the analysis exemplifying the conditional orientation and investigating its discursive contents by focusing on the ways in which workers position themselves and colleagues in relation to physical strain and deterioration. Of key interest to this analysis are the ways in which behaviors related to physical strain and deterioration are linked to the characteristics describing the category of the ideal worker.

In adopting a common agreement within sociological and psychological research, that positive social recognition is very desirable to most people, and that it can be a driver for conduct and relational adaption (examples are Bourdieu 1996; Gergen 1991; Honneth 1996), it becomes hard for the worker to practice a sort of behavior that is discursively produced as negative. Thereby characteristics of the inadequate or inferior worker become the unattractive counterpole describing workers or persons not likely to receive positive recognition in the construction industry. Maintaining a focus on characteristics describing the ideal worker and the inferior worker as such becomes a central analytical perspective as these characteristics frame the space for successful positioning within work.

\section{Research design and methods}

The empirical basis for this article was conducted by performing on-site, individual interviews with 32 construction workers in eight construction gangs distributed across 
eight different work sites. The construction gangs were identified in collaboration with the nongovernmental organization, the Construction Industry's Health and Safety Bus (CIHS-Bus) (Byggeriets Arbejdsmiljøbus). CIHS assists companies, safety representatives, and employees in developing and ensuring safe and healthy working conditions through preventive measures. The service is financed by the trade unions and employer associations. By following the CIHS-Bus consultants' daily work we gained access to the workplaces and the construction workers. Along with the CIHS-Bus we visited 19 different larger construction sites to find a somewhat representative combination of construction sites representing the differences between ways of relating to physically straining work.

Two cases were strategically selected because they according to the CIHS-Bus are widely known to be some of the leading firms in the Danish construction industry regarding concerns and innovation on occupational health and safety, thereby making them critical cases in the terms of Bent Flyvbjerg, allowing generalizations on the basis that "If this is (not) valid for this case, then it applies to all (no) Cases" (2006, p. 230). On this basis, it is reasonable to assume that if these companies have challenges with physically straining work-being widely recognized for their efforts-companies less known for their efforts are very likely to have the same or worse challenges.

The six other construction gangs were chosen more on an explorative basis during our visits, emphasizing that these companies to our knowledge did not hold any special reputation in relation to occupational health and safety. We employed an explorative approach as our research questions emphasize a great openness toward the research topic.

For both case types we had general demands that only large construction sites where gang organization was present could participate in our research and that four different professions had to be represented. Our focus in the study was on scaffolders, carpenters, concrete workers, and bricklayers. These professions were chosen because they were objects of political attention from both employers' association and the union, which makes good sense as these professions have severe challenges with MSDs.

As all gangs were willing to participate, we conducted the interviews with the ones first available for participation and carried on making arrangements until stories and descriptions to a severe degree became saturated and it seemed that little new information would be conceived from this explorative approach. ${ }^{5,6}$

The gangs participating in the study consisted of one concrete worker gang, three bricklayer gangs, two scaffolding gangs, and two carpenter gangs. All gangs except for one carpenter gang were employed on piece rate contracts. In this last gang, members worked on hourly pay.

In each of the eight gangs, two to five workers were interviewed. The reason for not interviewing the same number of gang members in each gang lies within the organization of work in the different construction professions. In scaffolding, work is usually organized in gangs consisting of two to three workers building and dismantling scaffolds with the responsibility of one or more construction sites depending on the size of the site. In the other professions, work at larger construction sites-on which this study focuses-is usually organized in larger "single-profession" gangs working on a common piece rate contract of, in our cases, up to 20 workers.

Interviewees were selected on the basis of age so that the interviews would represent perspectives from young/inexperienced workers as well as older, more experienced 
workers. Furthermore, the occupational health and safety representative ${ }^{7}$ in each gang (except one) was interviewed as we found it especially interesting to include perspectives from the workers assigned with communicating and negotiating occupational health and safety between the gang and the construction site management, as he was expected to take up a central position of agency in relation to the work gangs' focus on physical strain. In one of the best case gangs we also interviewed the site foreman; in the other we interviewed the employer. In the cases where we interviewed the employer, he was allowed to pick out our informants from his company and emphasized the point that these were the most health and safety concerned employees in the company.

Except for these criteria, we applied a nonprobabilistic convenience sampling strategy, that is, we asked arbitrary workers to participate. All workers were offered a minor economic compensation (circa €20). In total, 32 workers were asked to participate, none of these refused.

\section{Interview methodology}

We view the interview as an appropriate form of empirical production in relation to the aims of the study, as it gives an insight into the discursive practice as perceived by the interview person. As follows from the analytical perspectives employed in the article, we should interpret not only relations between the construction workers but also the product of the interview as constructed in the power relation immanent in the interview situation. As researchers, we define and co-create the knowledge produced in the narratives of the interviewees. As such the product of the interview must be perceived as the situated product of the negotiated practice and room for self-presentation between interviewer and interviewee described by Margretha Järvinen as interviewing in an interactionist framework (2005). Validity upon the narratives of the subject it aims to investigate is promoted as the interview person draws on the categories and perceptions of work, body, organization, and conditions she/he recognizes, and uses these to promote at picture of a consistent, recognizable and rational behavior during the interview (Järvinen 2005). When this methodological approach is to be the basis of the analysis of discursive practices, power relations and resistance it does however place a demand on the researcher to not impose perspectives on the interview person, while still challenging and interestedly asking about the rationalities playing part in the presented perspectives.

The interviews were performed following a semi-structured guideline covering vital research questions including perspectives drawn from research on safety culture in the construction industry but leaving room for subjective narratives and perceptions from the interviewees (Järvinen 2005; Kvale 1997). The interviews were of lengths reaching from 45 minutes up to 1 hour and 20 minutes. For the analysis, interviews have been systematically listened through, and presentations of anecdotes, stories, presentations of views on own and others' behavior, conformation or resistance to norms or practices have been drawn out to provide basis for the analysis of the discursive practice of deterioration and physical strain. To emphasize transparency of the analysis, we draw out examples of discursive reproductions of practices and analyze these openly within the text, as well as referring to the more general findings of the study. 


\section{The conditional orientation toward physically straining work and deterioration}

Without a single exception, interviewed workers described ways in which they perceived work to have problematic effects on their physical well-being. To gain an insight into the discursive practice of physical strain and deterioration, we first need to exemplify the conditional orientation which so thoroughly traverses the narratives of workers. This will also contribute in our undertaking of the initial cuts in the dissection of the discourse.

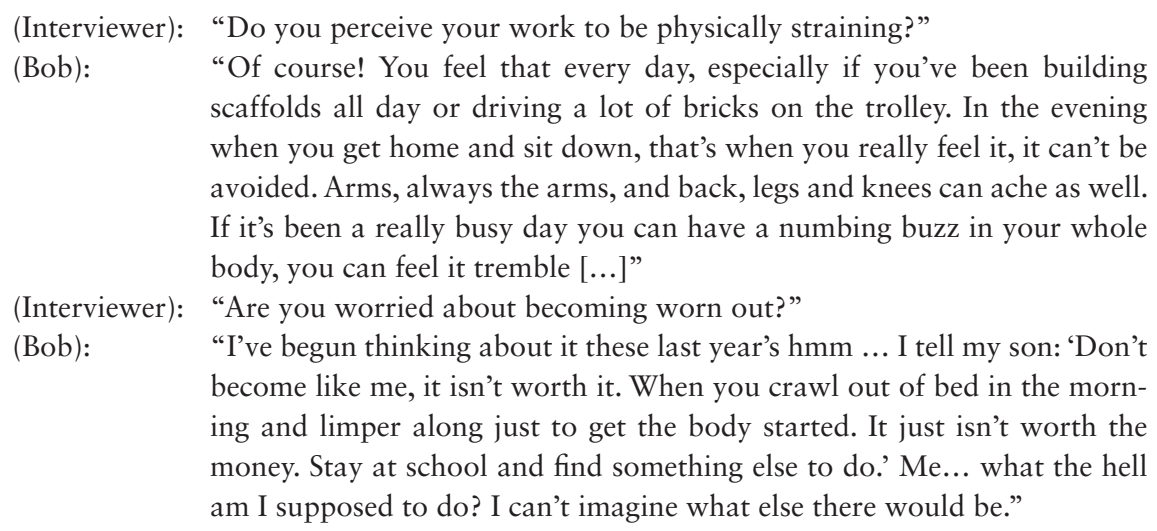

(Bob 38, laborer)

At a relatively young age, Bob describes how he perceives the effects of the hard work; the immediate buzz in the evening, as well as the sign of more long-term deterioration in his limpering along. Bob suggests a relation between the strain and the pace of work as on the really busy days. He positions himself reflexively as occupying a powerless position in relation to the deterioration and strain in saying: "It can't be avoided."

Of importance to the understanding of the powerlessness that workers experience are also the last words in Bob's quote: "Me ... what the hell am I supposed to do? I can't imagine what else there would be." Many workers describe themselves as being in a situation where they have very few ideas of what to do if they did not work in construction. Supporting a family and maintaining a certain standard of living is described as very difficult if you need to restart your career in another profession without education, making the alternatives unemployment allowance, students allowance, or (even more) low-paid work, with a substantial decrease in living standards as a consequence.

Bob does have a notion of resistance. Not one that lies inside the work, but one that involves himself advising his son not to become a construction laborer. Observably, Bob is not alone in this perspective. Several workers show a similar approach to the habitus produced by their trade; that their children should not become construction workers. This has also been pointed out in recent labor union media (Jensen 2012). Following Bourdieu's concept of social capital, arguing that children are likely to take up similar professions to their parents' (1996), the construction worker's warnings in the care for their children appear as a reasonable strategy, based on the conditional orientation toward physical strain in relation to work. 
As Vad and Kines show in their analysis (2011), and as is customary for the workers' descriptions of practice, the conditional orientation toward physical strain and deterioration in the construction work stands very strong. It is a dominant discourse, conformed among almost everyone engaged in the industry. Following the positioning theory's analytical framework, we must now ask ourselves: To what does Bob refer when he concludes that "it can't be avoided?" He refers to a certain discourse upon the characteristics of construction work; a dominant conceptualization of reality pleading for examination. So forth we argue this to be interpreted as: It can't be avoided, under the given circumstances. This interpretation enables the question of why strain becomes such an integral part of construction work. To better understand this, we investigate the discursive practices upon body, pain, and physically straining work that coproduce the worker's habitus; the physical and social practice that the worker must apply upon himself to become a legitimate participant in the social frame of work that is the gang. These topics must be investigated because they have shown to be intrinsically related to the conditional orientation toward physical strain in the work.

\section{On physical capacity-use of the body in the search for flow and rhythms in work}

The conditional orientation toward physical strain in construction work can be identified as reproduced through the workers' search for flow and rhythm in work. To have a good day of work implies that tasks are not interrupted, delayed, or broken up into too many different tasks. Workers often describe how they appreciate the feeling that something is happening, that production is really going on:

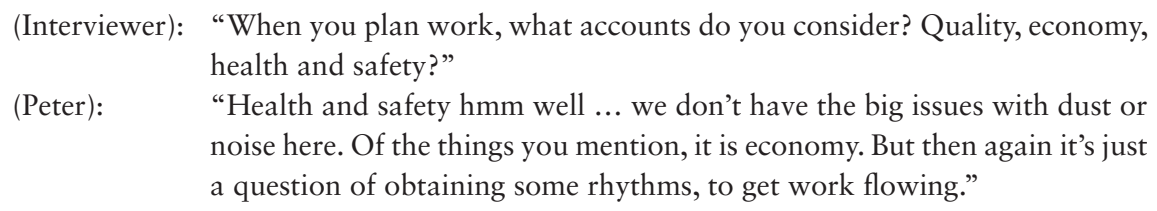

(Peter 32, bricklayer)

This search for flow in the sense of uninterrupted work and the possibility of concentrating on work tasks can be interpreted as a positive way of gaining flow and meaning through work (Csikszentmihalyi 1996) and is emphasized by most workers. In the further investigation of the certain meanings, flow and rhythms are ascribed in the construction gangs; it does, however, become clear that flow and rhythms themselves are not the only aspects of work affected by the search for these.

"You adjust all the time ... you could say 'work at maximum effort all the time.' So for instance, if it's a brick layers scaffold, you might walk slower because it's heavier. But you still work at maximum capacity, based on your physical capacity, if you get what I mean.”

(Brian 29, scaffolder)

As such, the search for flow and rhythms during work is not just a search for any rhythms, it is a search for rhythms optimized to fit the maximum physical capacity of the 
worker. ${ }^{8}$ Drawing upon the generalizing operator of "you do," the reasonable worker is characterized as one who works at maximal physical capacity. This characteristic is stressed by the workers as an important quality in a good colleague several times.

But digging into this issue, the rationality behind this search for optimizing must be exposed, and here seems to be two rationalities at stake: (1) In the pieceworking gangs, workers describe that without providing maximum effort, you don't make any money. (2) In both the hour-paid and the pieceworking gangs, workers seem to some degree to align themselves with the objectives of their company, describing that if you do not cut corners in regard to the health and safety regulations, your work rate will be too slow and somebody else will be hired. Alternatively, the company will not be able to compete and either way you will not have a job tomorrow. In subjecting themselves to these rationalities, there is a need for the construction worker to put in an effort at a rate close to physical maximum all the time:

"We're also under pressure on our piecerates from our firms now because ... they need to be competable. And there are fewer and fewer jobs, with more and more demand. So people keep undercutting each other, which hurts our piecerates, and then we run faster."

(Albert 31, carpenter)

This mechanism depicted by Albert, that competition puts pressure on the intensity of work, both in itself, as acceptance of poor health and safety conditions tend to become higher, and also through the piecerates, is by no means a new phenomenon in the construction industry. Looking into historical sources, it becomes clear that the piecework has been a constant challenge to handle for both workers and employers since its blooming in the middle of the $19^{\text {th }}$ century, and that competition within the industry-also historically-has been fierce (Nørregaard 1943). Workers also describe that during the financial high times, they tend to want more. So forth we cannot simply blame the current fiscal crisis for this tendency.

There is an apparent economic advantage for both worker and company in seeking a form of organization that incites behavior within the work gang that maximizes working rhythms based on physical capacity. In a very descriptive way, Bob gives an example of how this is practiced:

(Interviewer): “Is there a culture where pace is so high that you can't say no to deterioration?"

(Bob): Most definitely yes, you have got to lower the pace, it's wearing people out, that's for sure! Also, there are times when you could have done a task in a better way, but instead you do it in a faster way, straining a bit more. But you get it done faster. Could be when you need to lift or carry something, then instead of finding something to lift with, or calling for the truck, you just get it over with quickly. In that way, you try to get things done quickly, but it's physically straining.”

(Bob 38, laborer)

The orientation toward flow and rhythms in the construction gangs is drawn in directions describable to a large extent by the concept of brutal rhythms. The concept of 
brutal rhythms draws upon a wider discussion of rhythms as a significant part of human lives-with the body as the central part of departure. Rhythms structure needs, life cycle, social relations, society, movement, and so on. Henri Lefebvre emphasizes the point that rhythms and especially their mutual interactions can be understood on a continuum of harmonious coexistence (2004). As such, the internal rhythms of the construction workers' bodily functions (needs for restitution, nurture, physical capacity building, etc.) are to be seen as colliding with externally imposed rhythms of work at maximum physical capacity; Lefebvre describes this collision of different rhythms as arrhythmia (2004).

The concept of brutal rhythms is further developed by Hvid (2010) and points to an organization of work emphasizing certain characteristics from the Taylorization era's division of work processes into their singular, repetitive parts and thereby to increased risk of unilateral repetitive loads and loss of sense of meaning in work. This traditionally collides with other rhythms in the lives of people such as the bodily rhythms we see described through the narratives of the construction workers.

The worker's maximization probably does not lead to a significant increase in unilateral repetitive loads as these are currently agreed to be relatively rare in construction, but rather, the search for cutting corners to increase the pace of work to fit this maximal physical capacity of the individual seems likely to increase the number lifts, their load, and the time spent working in awkward positions. In this manner, the concept of brutal rhythms can be used to understand a very important part of the construction workers' conditional orientation toward physically straining work, as there is a commonly perceived need to conform to these rhythms. At the same time, the concept of brutal rhythms should be expanded to contain types of work which does not necessarily lead to unilateral repetitive loads but also to rhythms that become brutal to the worker in terms of other types of strain, e.g., fatigue.

This practice can be seen in parallel to a French study of construction safety as Sanvert shows an association between time pressure and the accelerated production methods employed in construction work, and an increase in the number of accidents (1991). In the same way, this search for brutal rhythms seems to affect the willingness to conduct physically straining work and thereby the risk of suffering from MSDs. In the same breath, let us not forget that Bob himself points toward a solution to the problem in lowering the pace of work. He, as well as most other workers just do not see this as a realistic option, because of the competition, time pressure, and economic incitement.

An interesting perspective in this relation is the position that foremen and employers take when describing the way in which they try to guide workers to abide by occupational health and safety legislation and standards. A very common notion among employers is to provide the necessary assistive devices needed to perform the work in accordance to occupational health and safety legislation, but getting workers to actually use them to lower their strain and follow legislation is described as a completely different matter:

(Interviewer): “Are you consequent enough as an employer in making your workers follow health and safety regulations?"

(Ralf): "No, I don't think so. But at the same time I'll have to tell you that we're probably the most consequent in the business. The problem is, that if the whole industry are down here (gesticulates) and were up here, then we can't get all the way up here (gesticulates again), because the difference 
becomes too big. If we consequently fire people every time they trespass, then nobody will want to work here. They'll work other places where they can do as they see fit. [...]

If you want to work in accordance to the law, then it will demand way more planning than you have today, I mean ALOT more. And that means costs, it means sending out white collars to observe the work all the time ... and that's where competition kicks in, right."

(Ralf 53, employer)

Even though the employer has an obligation to make sure the regulation is being followed by his employees, he positions himself reflexively as being in a position of powerlessness in confrontation with the workers' practice of work. In this way he and his company accept the pursuit of brutal rhythms that are reproduced in the discursive practice of the gang. In addition to this, he also positions himself in relation to a structural perspective on the industry, as powerless in the face of competition that extends to the area of health and safety even though regulation is violated. This is interesting in relation to former research on disability and accident prevention in the construction industry as both Gervais (2003) and Choudry et al. (2007) point out unequivocal managerial support as a determinant factor for successfully implementing safety objectives and measures. What is shown here is that following this rationality, competition forces employers to not take responsibility. This disclaiming of responsibility should, however, be interpreted in the light that employers leave the on-site organization of work to the work gang and at the same time often provide the gang with a financial encouragement (higher pay and/or future employment) in getting the job done as fast as possible, thereby in effect supporting the culture of physical strain rather than providing the firm, unequivocal managerial support that might be needed.

This clarifies how the conditional orientation toward construction as physically straining is reproduced through a mutual acceptance of the search for brutal rhythms. Construction worker and employer can be perceived to have made an unspoken agreement that bodily regards cannot be taken too serious as this consideration is economically costly to both parties. As shown in the introduction however, the part suffering from shorter working life and earlier experiences of chronic pain and disability is the worker.

\section{Habituating pain in the reproduction of working conditions}

To further understand the complex discursive objects forming the conditional orientation toward physical strain and to deterioration, we need to closely examine what sort of conduct workers must subject themselves to, in order to receive positive recognition through work. In this analysis, certain necessities in the handling of pain emerge in the narratives of workers:

(Interviewer): “What sort of infirmities do you experience?"

(Brian): "It can be the back or the arm that aches. It is sort of a strange job this one, right... because even though you ache, you just go on. You know, you don't want to let the others down, right. So you're still out there working $[\ldots]$ you learn to ignore it, you just do" 
(Interviewer): “You don't listen to your body?"

(Brian): No, not at all. And another strange thing I've noticed. When you go to the toilet, well we don't have a toilet, so we go on for like 12 hours without a pee. You just learn to ignore the need to go, and when you're at home for the weekend, you don't notice till it's almost too late. All those small warning signs your body gives, you simply don't notice. And it's the same with the pain. It becomes a matter of habit."

(Brian 29, scaffolder)

Examining the subject positions that are opened in Brian's narrative, it becomes evident that certain positions in relation to handling pain and being a good colleague crystallize. When stating that "You don't want to let the others down," Brian invokes the power of the generalizing operator you as in everyone with any self-respect. As a man comprehending to the dominant discourse, Brian reflexively positions himself as not being the kind of guy that lets the others down. In the narrative this implies going on, showing the stamina required, ignoring or rather habituating pain, in the sense that you learn to live with it and continue work regardless. Brian simultaneously interactively positions the ideal colleague or worker as a person displaying these characteristics. Through the meta-conversation not displaying these characteristics thus becomes the signs of the inferior worker.

Other characteristics describing the ideal worker and colleague in the narratives of the workers include enjoying hard labor, being self-sufficient in handling work even in handling loads far exceeding the Danish work environment laws, as well as appreciating soreness of the body after work. All these attributes describing the ideal construction worker contribute to the description of a person that, to a severe degree, habituates the experience of pain and does not react to either pain or lesser impairments in bodily functions as long as he can actually go to work, and work at the same pace as the rest of the gang. In several instances, workers describe that reacting to pain by staying at home or calling in sick happens only if you suffer a condition that completely or almost completely disables your ability to work. At the same time, there is a negative positioning of taking bodily well-being into account, of saying no to tasks that are too hard, either because they might be badly planned or because of the lack of technically assistive devices, of asking too much for help and of being too fussy about occupational health and safety.

When prioritizing bodily well-being in different ways, rather than accepting pain as well as the other above-mentioned positively connoted characteristics of the ideal worker, are negatively produced characteristics, displaying these might very well be reasons for criticism and exclusion, which the interviews also show.

\footnotetext{
(Interviewer): "Do you discuss physical strain in the gang?"

(Flemming): "Yeah, we might be cursing and swearing about some task, but then someone always has a quick remark like 'if you don't like it, find another job!"”

(Interviewer): "Would that be someone from the gang saying that?"

(Flemming): "It was the foreman"
}

(Flemming 23, carpenter)

It seems that the room for positioning yourself as unsatisfied with having to conduct physically straining work is very limited if you want to be a successful part of the work gang. This ushering toward the display of certain characteristics shown throughout the 
study to be very common can be seen in close relation to a notion that Gherardi and Nicolini in their studies of Italian construction workers' safety practices describe as "sustaining the narrative of the virile male" (2002, p. 205). Also, Choudry and Fang in their study of Hong Kong construction safety experience this sort of reflections, where people feel a need to uphold a certain type of "tough guy" image (2008).

From these perspectives, a link can be drawn between the discursive practices of physically straining work and pain, on the one hand, and the reproduction of a set of very traditional Euro/American working class masculinities, on the other hand, as presented by Connell (1993).

In this sense, the historical disposition of the construction trades as "male jobs" can be drawn into an explanation of why physical strength, stamina, self-sufficiency, and the ability to earn money are reproduced as so valuable characteristics. At the same time, we see that the display of these characteristics becomes central to the workers' inclusion in the work gang, as the habituation of pain and display of these masculine characteristics become part of the professional identity of the worker. By habituating these characteristics, the workers themselves contribute in the reproduction and strengthening of the conditional orientation toward construction work as physically straining.

We should not, however, become seduced to think that these reproductions of masculinity in relation to physical strain take their form only as Tarzan-like displays of brute strength or macho bravery, as has been produced as a truth about conduct in the construction industry (Liversage \& Knudsen 2011). Also, we must understand the reproduction of these masculine characteristics as form of the subjection to what needs to be done in silent determination-hence a conditional orientation. This sheds a new perspective on working class masculine norms as norms helping the construction worker maintain a positive, meaningful identity while performing physically straining and painful work.

The conformation of physical strain and pain as inextricably linked to work in the construction gang can be further identified through a very common strategy for handling pain: the use of pain medication as a means to continue work in spite of disabilities and pain:

(Mike): $\quad$ "I am in pain every day, as I sit here my back hurts. It pinches and I hurt like hell, and my hands hurt too. It has been like that ... well it's just a habit, then at times it gets even worse, then it's like uuaah."

(Interviewer): “Then what? You take some medication? (I'm asking this cause he told me the day before)"

(Mike): "Yeah, well I try to keep it down because it destroys your kidneys and shit."

(Interviewer): "What sort of medication?"

(Mike): “I don't know, it's something for arthritis, something highly painkilling”

(Interviewer): "How often do you take it?"

(Mike): "Two-three times a week."

(Mike 45, concrete worker)

Many workers explain that they change jobs so often that they do not earn full rights for sick leave payment (six months full employment) and many workers above 35 years of age take painkilling medication on a regular basis in order to go to work or to be able to move around when they get home. This rather massive habituation of pain that takes 
place within work, in conjunction with work characterized by many predictors for MSD (Andersen et al. 2007) and the positive recognition linked to displaying stamina, not letting down colleagues, and not saying no to hard work tasks, seems to lead to a conduct highly characterized by presenteeism as described by Hansen and Andersen (2008). Presenteeism understood in the sense that construction workers show up to work regardless of actual sickness, pain, or disabilities, and that this takes place in a wide extent, which in the long term becomes costly to both the individual and to society.

It seems Foucault's concept of political anatomy, in the sense of institutions or systems working to discipline people in certain ways, can be put to new use in the world of the construction worker (1977). The workers' optimizing of bodily resources toward brutal rhythms in the competitive economy of the construction industry leads to a certain orientation with the docile body as its object: In popular terms known as the ergonomic trap; the "risk" that sometimes an organization turns the principally strain-reducing technology into productive efficiency at the cost of concern for deterioration (Westgaard \& Winkel 2011). However, in the discursive practice of the construction gang, the ergonomic trap cannot be seen simply as a trap; something you fall into because of your lack of attention. But neither as the employer's sole interest in increased efficiency and profits (even though that part probably does not bother the employer). Rather, we argue that the mechanism involved in the conditional orientation toward physically straining work is a habituation or institutionalized mental structuration making the construction worker optimize his effort toward brutal rhythms as an auto-optimizing, reproduced in the discursive practice of masculinity, norms for a job well done, and the structures of economic encouragement.

Also this investigation of construction worker's reproductions of the need to subject themselves to physical strain and pain contributes to a better understanding of why deterioration in the construction industry is higher than an average among job groups in spite of the technological development of many assistive devices.

This plays into a discussion of the piece rate system and of production bonuses in the Danish construction industry. Swuste et al. have a notion that economic incitement can be counterproductive to safety measures (2012), and also Choudry and Fang identify this as a problem for safety culture in Hong Kong's construction industry (2008). This seems to be perhaps even more the situation in the case of physically straining work and also shows how displaying the formerly depicted characteristics should be perceived as rational action in the sense that it leads to social inclusion and economic security and gain.

What further becomes interesting when identifying this reproduction of strain and pain as conditions for work are some inconsistencies in the descriptions of self-responsibility related to the deterioration that many workers suffer from:

"I like that concrete work, that's a profession where you ... well it's okay that you're sore in your body when you get home. Of course you shouldn't wear yourself down as I've done. But that's just because I've been stupid ...."

(Jens 48, concrete worker)

This articulation of the worn-down worker as stupid is very common among the workers' narratives, pointing toward an understanding of the individual worker as self-responsible for the deterioration that he suffers. Many workers describe this as a 
consequence of their willingness to "just tackle the hard work," which should be seen as part of the reproduction of masculinity as described. What is very important to notice here is the inconsistence between the description of physical strain and pain as unavoidable, on the one hand, and the (reflexive) positioning of the worn-out worker as being self-responsible for the deterioration he suffers, on the other hand. The workers manage to describe themselves as both powerless and responsible at the same time, and this takes place even within the narrative of the same individual worker. Drawing on the term first described by Gregory Bateson (1979), and later put into a working life context by Jens Gudiksen (2007), this situation where workers describe themselves as both responsible and powerless can be interpreted as a double bind to physical strain and deterioration, wherein the worker finds himself in a situation with apparent choice but only one inherent option allowing him to participate and maintain his position in the work.

\section{Conclusive discussion}

Condensing the perspectives from the analysis, a number of perspectives as well as subject positions become clear. Setting out to denaturalize or deconstruct the conditional orientation toward physical strain and deterioration in the construction industry, we come across several interesting discoveries.

First of all, the mutual understanding between worker and employer that physical strain is unavoidable means that the responsibility for it has disappeared in a subtle way; this is a most distinguished quality of the conditional orientation: The worker finds himself powerless in facing physical strain and deterioration seen as inevitable through work under current conditions, but is at the same time positioned as being self-responsible and stupid when suffering actual pain and impairment. In addition, the mutual understanding between worker and employer that physical strain is unavoidable means that the responsibility for it has disappeared in a subtle way. Not having a center or a responsible manager but rather as inherent in the system of organization and the discursive reproduction of the ideal worker's qualities, the force or power that makes the worker toil under high pace and disregard for bodily well-being has been hidden in a system that seemingly has no core. This missing core, the agent or employer that directs a certain behavior, means that the worker must turn the gaze upon himself; he participated in the organization of work in the gang and therefore he is responsible for his own deterioration. This double bind places the worker in a weak condition to take action in relation to his own position as he finds himself responsible for the strain he submits himself to, but at the same time cannot perceive alternative ways of working as this leads to risks of social and professional exclusion and possible unemployment. This double bind is an important part of the conditional orientation.

Summing up the specifics of the conditional orientation toward physical strain and deterioration, our focus on the subject positions ascribed to the ideal colleague or worker in relation to handling physical strain and pain holds a great explanatory strength in understanding why construction workers view deterioration and physically straining work as conditions in work: The ideal worker is characterized as a person who likes hard labor, habituates pain and does not talk too much about it, shows stamina, goes on regardless of obstacles, is self-sufficient in handling work and does not ask too much for help, appreciates soreness of the body, and seeks flow and rhythms with a high pace 
that seems brutal to the body. Displaying these characteristics is very likely to increase the risks of suffering from MSD in the long run. As at the same time, not displaying these characteristics or displaying characteristics such as taking bodily well-being into account, calling in sick, saying no to physically straining tasks, asking too much for help, or being fussy about work environment becomes the unattractive positions of workers subject to criticism by either employer or colleagues or even subjectified as not being fit for construction work.

These discursive constructions of the ideal construction worker in juxtaposition with the forms of economic encouragement-emphasizing financial reward and/or employment security through high pace and competition through disregard of occupational health and safety-have strong explanatory force as rationalities behind the conformation of the conditional orientation toward physically straining work in the construction industry. If there is a wish to lower the risk of MSD associated with construction work, it seems reasonable to direct attention to these forms of encouragement, time pressure, and competition, and also to the norms we describe and to view these as intimately linked to each other and mutually reinforcing.

Also, the analysis puts a question mark to the earlier understandings of gang work as a means of influence and relative freedom for the construction workers: At least in the area of handling physically straining work, the gang seems ill fit as a collective framework for protecting the body, as the characteristics of the ideal worker leaves little room for this. The regard for bodily well-being becomes an individually tied obstacle for the collective goals and values of the gang.

The landscape painted by the analysis may seem very uniform and uncontested, which was one of the initial reasons for exploring its meaning. However, we have sought for contradictions to the conditional orientation, and have in our interviews only found one person actively seeking to resist the depicted norms and practices in order to maintain a room for caring for his health. Going further into an investigation of ways of resisting these practices would certainly be of interest, but we would not currently expect to find much in this regard.

Following up on our two best case companies, the one worker displaying an alternative practice was from one of these companies, but he explained that he was the only one with this focus and was seen as somewhat abnormal by his colleagues. At the same time, all other interviewed workers in these companies very much shared the conditional orientation toward physical strain. Conclusively on this methodological perspective, we can see that these companies do have an extra attention toward providing the necessary assistive devices, but that the same norms, forms of incitement, types of employment, time pressure, and competitive frames were present as in any of the other companies.

Further supporting this lack of alternative discursive practices, we rather see workers coping with the demands within the hegemonic discourse, taking medication or advising their children not to choose the profession. Bringing in wider sociological perspectives on these sorts of coping, there are things to be gained by further examination of parallels between strong historical forms of organization and culture within construction, and the development of work trends, organization, and state on a global level: The construction industry's century-long traditions for work in gangs seem very similar to team organization which has since become common practice across almost any profession today. Changing workplaces, unsecure, short-term and changing forms of employment with following employment-dependent social benefits, as well as high levels of competition are historically tied to construction work (Andrésen 1984; Applebaum 1999; Morton 2002). But these are 
conditions highly emerging across the global labor market, globally creating precarious labor relations and increasing social inequality (Standing 2009). Drawing on perspectives from the analysis in this article, we-as a society-should be careful in pursuing these sorts of conditions for work, as in construction these perspectives play a great part in producing the conditional orientation toward physically straining work, thereby coproducing deterioration while silencing notions of alternative discursive practices. Conditional orientations exist within all forms of work, but there is a necessity to question these and leave room for alternative discursive productions in order allow people, workplaces, and professions to develop increasingly sustainable forms of existing.

When looking for possible fields of change on the basis of the analysis, attention could be turned to the powerlessness presented by workers and employers in relation to a competitive situation within the construction industry, where competitiveness comes at the cost of concern for the bodily health of workers. The competition is described as so determinant that legislation in the area cannot be abided as this will cost the companies assignments. Following Foucault's analysis of the purpose of legislation in Discipline and Punish, this must be interpreted as a failure of enforcing the law (1977). If enforcement of the law does not serve to deter potential perpetrators from illegal action, if illegality rather than legality is the norm, the practice of the law does not work, at least not to its letter. This leaves a rather obvious area for action in aiming to change the discourse upon strain and deterioration in the industry, in addition to a focus on the formerly mentioned perspectives. It should, however, be noted that since the building industry nowadays entails global competition, changing the rules in one country may not do the job. As such, some of the foundations for a solution to the juridical inadequacy seem to have relations to at least a European level of politics.

We find that the concept of the conditional orientation holds a powerful explanatory force in understanding the complexity and troublesome nature of decreasing MSD in the construction industry. In conceptualizing and questioning this initially perceived wall of impossibility, we have obtained a much more nuanced understanding of discursive objects mutually constituting and reinforcing construction workers' sense of work as something that has to be physically straining and include the experience of pain.

Two main parts in the constitution of the conditional orientation are shown to be the ability to pursue brutal rhythms and to habituate pain as parts of being an ideal construction worker. In themselves, these perspectives are important sociological contributions to understanding the presence of risk factors for MSD in construction work. Understood as mutually interacting in the reproduction of the conditional orientation toward physical strain, these perspectives provide an even stronger connection as habituating pain clearly aids the worker in the persuasion of the brutal work rhythms. The other way around, habituating pain makes good sense if you have a conditional orientation toward it.

Our use of these perspectives could, however, also serve as analytical tools in many other areas of work just as the notion of the conditional orientation.

\section{For further research}

Following up on our ambition of bringing sociological perspectives into the analysis of a traditionally physical, biomedical, and epidemiological problem area, we contribute with some perspectives on why people do not easily lower the physical strain they submit themselves to: neither by the consequent use of the best assistive devices, by saying no to too 
hard tasks or tasks with too short timeframes, or by making sure to require help for heavy lifts and so on. This provides some explanation as to why focus on the transfer of bestpractice has so scarce effects in the construction industry, as described in various domestic and international studies by Winch (1994), Morton (2002), Dyreborg (2006), as well as Vad and Kines (2011). The transfer of best practice and cultural changes seems to require different conditions for its successful implementation. As such we have shown a part of the context in which the good ergonomic knowledge and advices must struggle to gain a hold. Investigation of the effects of more stable employment conditions along with a focus on cultural changes are-based on this study-likely to lead to improvements in the need for workers to submit themselves to physical strain. In order to really bring the perspectives from this article into practice, intervention studies with high focus on creating the conditions for alternative discursive practices would be of great interest.

Even though this study is based on empirical productions from a Danish construction context, these perspectives seem to have an explanative force in relation to construction work elsewhere. Construction workers across the Western world are described in sociology as displaying and appreciating similar qualities of physical character in relation to work (Applebaum 1999; Choudry \& Fang 2008; Gherardi \& Nicolini 2002; Morton 2002). Still, it would be interesting to investigate other national contexts for construction work, as for instance Swedish and Danish construction workers exhibited differences in safety culture in research of the construction of the Öresund Bridge (Spangenberg et al. 2003).

On another area it would be very interesting to focus a study on the workers who have left the construction industry. Arndt et al. show that a large portion of disability pensions are based on musculoskeletal diseases (2005). But an interesting perspective would be to investigate the degree to which people prior to developing disability voluntarily leave the industry because of MSD-related problems or concerns.

The study shows that research on the relations between physical strain and the discursive practices of construction work can draw on a useful way from safety culture research as many perspectives are shared. Especially useful knowledge is to be drawn on perspectives such as time pressure, masculinity, the economic incentives, and managerial support. This study could, however, also contribute to the research on safety culture as we emphasize the mutually reproducing relationships between these perspectives in the discursive practice of the construction workers. The presented perspectives add to a discussion as presented by Dyreborg et al. in arguing that traditional health and safety measures should be "extended to include substantial improvements in the physical and ergonomic work environment" (2010, p. 599). The study shows that severe changes in the way of managing health and safety, culture and organization of construction work may be needed to effectively lower the risk of MSD associated with working in the construction industry.

\section{References}

Andersen, Johan Hviid, Jens P. Haahr, Poul Frost (2007) 'Risk factors for more severe regional musculoskeletal symptoms-a two-year prospective study of a general working population', Arthritis and Rheumatism, 56(4): 1355-1364.

Andersen, Lars Louis, Ole Steen Mortensen, Jørgen Vinsløv Hansen, Hermann Burr (2011) 'A prospective cohort study on severe pain as a risk factor for long-term sickness 
absence in blue- and white-collar workers', Occupational and Environmental Medicine, 68: 590-592.

Andersen, Lars Louis, Thomas Clausen, Hermann Burr, Andreas Holtermann (2012) 'Threshold of musculoskeletal pain intensity for increased risk of long-term sickness absence among female healthcare workers in eldercare'. PLoS One 7(7): e41287.

Andrésen, Carl Erik (1984) History of the Laborer Through 100 Years-Construction Work (We Were Not Slave Bound). Denmark: Fremad.

Applebaum, Herbert (1999) Construction Workers U.S.A. London: Greenwood Press.

Arndt, V., Rothenbacher, D., Daniel, U., Zscgenderlein, B., Schuberth, S., Brenner, H. (2005) 'Construction work and risk of occupational disability: a ten-year follow up of 14474 male workers', Occupational and Environmental Medicine 62: 559-566.

Bach, Elsa, Lars L. Andersen, Jakob B. Bjørner, Vilhelm Borg, Thomas Clausen, Mari-Ann Flyvholm, Anne Helene Garde, Åse Marie Hansen, Andreas Holtermann, Marie Birk Jørgensen, Pete Kines, Søren Peter Lund, Karina Nielsen, Reiner Rugulies, Ole H. Sørensen og Sannie Vester Thorsen (2011) Work Environment and Health in Denmark 2010_ Resume and Results. The National Research Centre for the Working Environment.

Bateson, G. (1979) Mind and Nature: A Necessary Unity (Advances in Systems Theory, Complexity, and the Human Sciences). Cresskill, NJ: Hampton Press.

Bourdieu, Pierre (1996) Practical Reason: On the Theory of Action. Stanford, CA: Stanford University Press.

Choudry, Rafiq M., Dongping Fang (2008) 'Why operatives engage in unsafe work behavior: investigating factors on construction sites', Safety Science 46: 566-584.

Rafiq M. Choudhry, Dongping Fang, Sherif Mohamed (2007) 'The nature of safety culture: A survey of the state-of-the-art', Safety Science 45: 993-1012

Connell, R. W. (1993) 'The big picture: masculinities in recent world history', Theory and Society, 22(5): 597-623.

Csikszentmihalyi, Mihaly (1996) Creativity: Flow and the Psychology of Discovery and Invention. New York, NY: Harper Perennial.

Davies, Bronwyn, Rom Harré (1990) 'Positioning: the discursive production of selves', Journal for the Theory of Social Behavior, 20: 43-63.

Dyreborg, Johnny, Harald Hannerz, Finn Tüchsen, Søren Spangenberg (2010) 'Disability retirement among workers involved in large construction projects', American Journal of Industrial Medicine 53: 596-600.

Dyreborg, Johnny (2006) In between paper and reality-the institutionalization of safety in the construction industry. Institut for Miljø, Teknologi og Samfund, Roskilde Universitetscenter og Arbejdsmiljøinstituttet.

Eriksen, W., Natvig, B., Rutle, O., Bruusgaard, D. (1998) 'Smoking as a predictor of longterm work disability in physically active and inactive people', Occupational Medicine, 48: 15-20.

Flyvbjerg, Bent (2006) 'Five misunderstandings about case study research', Qualitative Inquiry, 12(2): 219-245: Sage Publications.

Foucault, Michel (1976) 'Truth and power'. In Paul Rabinow, Nikolas Rose (eds.) (2003) The Essential Foucault, p. 300-318, New York, NY: The New Press.

Foucault, Michel (1977) Discipline and Punish-The Birth of the Prison. New York, NY: Penguin books.

Foucault, Michel (1978) The History of Sexuality Vol. 1-The Will to Knowledge. Translation by Søren Gosvig Olesen. København: Rhodos.

Foucault, Michel (1983) 'The subject and power'. In Paul Rabinow, Nikolas Rose (eds.) (2003) The Essential Foucault, p. 126-144, New York, NY: The New Press.

Foucault, Michel (2005) The Archeology of KNOWLEDGE, Translation by Mogens Chrom Jacobsen. Århus C: Philosophia. 
Frøyland, Kjetil, Heidi Enehaug, Lars Klemsdal, Steinar Widding and Jon Frode Blichfeldt in collaboration with Katrine Sandkjær Hanssen and Lars Martin Torget (2004) Dropout and Exclusion in the Construction Industry. Oslo: Arbeidsforskningsinstituttet.

Gergen, Kenneth J. (2001) Social Construction in Context. London: Sage Publications.

Gergen, Kenneth J. (1991) The Saturated Self, Dilemmas of Identity in Contemporary Life. New York, NY: Basic Books.

Gervais, M. (2003) 'Good management as a means of preventing back disorders in the construction sector', Safety Science 41: 77-88.

Gherardi, Silvia, Davide Nicolini (2002) 'Learning the trade: a culture of safety in practise', Organization 9: 191.

Gudiksen, Jens (2007) 'Modern management as double-bind communication', Tidsskrift for Arbejdsliv, 2.

Hansen, C. D., J. Andersen (2008) 'Going ill to work-what personal circumstances, attitudes and work-related factors are associated with sickness presenteeism', Social Science and Medicine, 67: 956-964.

Haraway, Donna (1991) Simians, Cyborgs and Women-The Reinvention of Nature. London: Free Association Books.

Hasle, P. (1982) Concrete work. An inquiry on technological development, work environment, health. Instituttet for Anlægsteknik, Danmarks tekniske Højskole.

Honneth, Axel (1996) The Struggle for Recognition: The Moral Grammar of Social Conflicts. Cambridge: Polity Press.

Hvid, Helge (2009) 'To be in control: the road to a good psychological work environment, learning and innovation?', Tidsskrift for Arbejdsliv, 1: 11-31.

Hvid, Helge (2010) 'Sustainable rhythms: when society meets nature'. pp. 15-31 in Aagaard Nielsen, Kurt, Bo Elling, Maria Figueroe, Erling Jelsøe (eds.) A New Agenda for Sustainability. Asgate Publisher Company.

Jensen, Klavs Buster (2012) '3F'union members will not recommend their line of work to coming generations', Fagbladet 3F. Internet source from: http://www.fagbladet3f.dk/ nyheder/social-og-arbejdsmiljoe/368dddaefbda4c0ca09ec9d8f1cb1752-201210153 fere-vil-ikke-anbefale-deres-job-til-brnene. Accessed October 15, 2012.

Järvinen, Margaretha (2005) 'Interview in an interactionist frame of concepts'. In Margaretha Jär-vinen, Nanna Mik-Meyer (eds.) Qualitative Methods in an Interactionist Perspective, p. 27-48. København: Hans Reitzels Forlag.

Karasek, R. A., Theorell, T. (1990) Healthy Work. Stress, Productivity, and the Reconstruction of Working Life. New York, NY: Basic Books.

Kvale, Steinar (1997) InterView-An Introduction to the Qualitative Research Interview. København: Hans Reitzels Forlag.

Laclau, Ernesto, Mouffe, Chantal (1985) Hegemony and Socialist Strategy; Towards a Radical Democratic Politics. London and New York: Verso.

Lazarus, R. S. (1999) Stress and Emotion: A New Synthesis. New York, NY: Springer.

Lefebvre, H. (2004) Rhythmanalysis-Space, Time and Everyday Life. London: Continuum.

Liversage, A., Knudsen L. L. (2011) Women in Construction Trades-An Interview Study. Copenhagen: The Danish National Centre for Social Research.

Mortensen, Ole Steen, Johan Hviid Andersen, John Ektor-Andersen, Hege R. Eriksen, Nils Fallentin, Poul Frost, Jens Peder Haahr, Merete Labriola, Mette Kreutzfeldt Zebis (2008) Sickness absence and returning to work in the case of musculoskeletal disorders-explanations and options. The National Research for the Working Environment, København.

Morton, Ralph (2002) Construction UK; Introduction to the Industry. Oxford: Blackwell Science Ltd.

MSD-committee report (2010) The parties committee for discussion of the prioritization of musculoskeletal disorders. In Danish: Trepartsudvalget til drøftelse af prioriteringen af muskel- og skeletbesver. Arbejdsmiljørådet og Arbejdstilsynet 2010. 
NFA (2012) Health and safety profile for the construction industry: completion of construction, http://www.arbejdsmiljoforskning.dk/da/arbejdsmiljoedata/arbejdsmiljoe-oghelbred-20/arbejdsmiljo-og-helbred-2012/arbejdsmiljoeet-i-tal/alle-svar-for-branchegrupper/diagram?group=AH2012_Branche36_003. Internet source 3/5/2013.

Nørregaard, Georg (1943) Arbejdsforhold indenfor dansk haandvork og industri 1857-1899. Institutet for Historie og Samfundsøkonomi.

OAAD (2013) Oxford Advanced American Dictionary. Internet source: http://oaadonline. oxfordlearnersdictionaries.com/dictionary/habituation. Accessed April 19, 2013.

OALD (2013) Oxford Advanced Learners Dictionary. Internet source: http://oald8.oxfordlearnersdictionaries.com/dictionary/condition. Accessed April 19, 2013.

Rankin, Catharine H., Thomas Abrams, Robert J. Barry, Seema Bhatnagar, David F. Clayton, John Colombo, Gianluca Coppola, Mark A. Geyer, David L. Glanzman, Stephen Marsland, Frances K. McSweeney, Donald A. Wilson, Chun-Fang Wu \& Richard F. Thompson (2009) 'Habituation revisited: an updated and revised description of the behavioral characteristics of habituation', Neurobiology of Learning and Memory 92(2): 135-138.

Sanvert, K. (1991) Building the Bâiment, the Risk Factors (Chantiers du Bâiment, les Facteurs de Risque). Direction Régionale du travail et de l'emploi, Île de France.

Spangenberg, Søren, Charlotte Baarts, Johnny Dyreborg, Lars Jensen, Pete Kines, Kim L. Mikkelsen (2003) Factors contributing to the differences in work related injuries between Danish and Swedish construction workers. Safety Science 41(6): 517-530.

Standing, G. (2009) Work after Globalisation. Building Occupational Citizenship. Cheltenham: Edward Elgar.

Swuste, Paul, Adri Frijters \& Frank Guldenmund (2012) 'Is it possible to influence safety in the building sector? A literature review extending from 1980 until the present' Safety Science 50: 1333-1343.

The Danish Construction Association (2006) Danish Construction-Professionals in the Construction Industry. Report by Zapera. København.

Ursin, Holger, Hege R. Eriksen (2004) 'Review-the cognitive activation theory of stress', Psychoneuroendocrinology 29:567-592.

Vad, Michael M., Pete Kines (2011) 'Construction workers perceptions and use of assistive devices I regards to musculoskeletal deterioration: a qualitative study', Safety Science Monitor vol. 15 issue 3.

Waddell, Gordon (2006) 'Preventing incapacity in people with musculoskeletal disorders', British Medical Bulletin 77-78: 55-69.

Waddell, Gordon, A. Kim Burton (2006) Is Work Good for Your Health and Wellbeing? London: TSO.

Westgaard, R. H., J. Winkel (2011) 'Occupational musculoskeletal and mental health: significance of rationalization and opportunities to create sustainable production systems-a systematic review', Applied Ergonomics 42: 261-296.

Winch, Graham (1994) 'The search for flexibility: the case of the construction industry', Work, Employment and Society 8: 593.

\section{End notes}

${ }^{1}$ Habituating here refers to the broader use of the word as "the action or condition of becoming used to something" (OAAD 2013). This is an understanding in line with the concept of habitus as developed in a sociological sense by Pierre Bourdieu (1996) rather than in a more psychological cognitive sense, as the declining behavioral response to repeated stimuli (Rankin et al. 2009). 
2 The concept of "condition" in this discussion draws upon the definition from the Oxfords Advanced Learner's Dictionary as "the circumstances or situation in which people live, work or do things" (OALD 2013).

${ }^{3}$ This does not mean a negligence of a material/physiological reality tied to the activity of human bodies building houses, but emphasizes the point that there is a long way from some materially bound necessity (of which we have little knowledge) and the organization of the Danish construction industry at present.

${ }^{4}$ This commitment upon earlier positions to which people have conformed into a sense of identity is also the reason why we find it so fruitful to combine positioning theory with the concept of habitus, which is the mental and physical structuration belonging to groups or individuals. The combination of the more contextual positioning theory in juxtaposition with the more sociological, structuralist habitus makes it possible to perceive social reality as both structured, but also constantly renegotiated.

5 This does not mean that there are no contextual differences, but it does mean that at the shown level of analysis, there are very clearly a number of dominant rationalities and institutional structures, forming discourse on the subject of physically straining work in the construction industry in a very profound degree. It is our argument that contextual differences are important to notice and to identify in order to perhaps move the industry in a desired direction, but this cannot all be accomplished in one article, and to notice the contextual differences, we find a good basis in first recognizing the contextual similarities as presented here.

${ }^{6}$ This of cause does not exclude the possibilities of learning from other perspectives, such as more singular focus on best case approaches or other types of selection basis. Flyvbjerg has a very refined discussion of this (Flyvbjerg 2006).

${ }^{7}$ In Denmark, each profession represented on the construction site must have a representative taking care of their occupational health and safety. This includes participating in safety meetings and communicating work environmental issues between management and the work gang. It could have been interesting to also interview Union representatives in the gangs, but these are tied to companies and therefore not necessarily present at every work site. As none were present on the sites visited, they were not included.

${ }^{8}$ Not in the sense that workers constantly sprint around, but rather as the maximum physical capacity possible over a full day of work. 